\title{
ESTRUCTURA RETÓRICA DEL PRÓLOGO PLAUTINO
}

\author{
Gilberto Castro
}

\begin{abstract}
RESUMEN
El objetivo de este artículo es analizar el "prólogo" plautino como una estructura organizada (una estructura retórica) vista en una relación social y cultural a través del teatro como un exponente de educación y de situaciones cómicas.

Dicho análisis está fundamentado en las teorías de la retórica clásica (Cicerón, Platón, Aristóteles, Quintiliano) y, además, en la neoretórica de Barthes y en las teorías lingüísticas modernas (Jackobson, Genette, etc.). Estas teorías nos ayudarán a analizar el discurso del prólogo como una estructura coherente en la forma y en el contenido. Los componentes retóricos que podemos observar a través de este análisis establecen la intención pragmática de una "retórica prologística", modalidad que, con los efectos teatrales, transporta al espectador y a los lectores, hacia el contexto retórico que generó el prólogo.
\end{abstract}

\begin{abstract}
The subject of this paper is to analyze Plautine's "prologue" as an organized structure (a rhetorical structure). It is seen in a social and cultural relationship through theater as an exponent of education and comic situations.

Such analysis is framed in the classical rethorical theories (Cicero, Plato, Aristotle, Quintilian), as well as in Barthes' neorhetoric and the modern theories of language (Jackobson, Genette, etc.).

These theories will help us analyze the discourse of "prologue" as an coherent structure in form and content. The rhetorical components that can be observed through this analysis, establish the pragmatic intention of a "prologue rhetorics", a modality that, with the theatrical effects, transports the spectator and the readers into the rhetorical context that generated the "prologue".
\end{abstract}

\section{Introducción}

Las obras literarias, según la tradición clásica, se conciben como una necesidad de preservación de las sociedades en las cuales los autores se circunscriben; así, en ellas están reflejadas, no sólo las actitudes del autor al componer una obra determinada, sino también los valores que esa sociedad origina y las circunstancias que favorecen la misma creación de la obra. Por lo tanto, el lector, en palabras de Eco, "no debe leerla solamente a la luz de sus propios códigos (nutridos y renovados por la aparición de la obra y por su asimilación por parte de la sociedad): 
debe descubrir el universo retórico e ideológico y las circunstancias comunicativas de las que partió en las condiciones de novedad en que la obra nació" (1986: 207).

Por lo anterior, nuestro interés es ofrecer otro modelo de lectura de Plauto a partir de los prólogos, los cuales constituyen verdaderas unidades lingüísticas por sus estructuras sintagmáticas y paradigmáticas bien definidas.

\section{El prólogo: análisis retórico de su estructura}

El prólogo se presenta como la vanguardia de la comedia y es parte integrante de ella: siguiendo los pasos de la construcción retórica constituye la primera parte del sistema: la dispositio; sin embargo, su particular información permite reconocer en su estructura y su enunciación todas y cada una de las conocidas partes de la retórica, de manera que puede ser extraído del texto completo y ser analizado como un discurso independiente, sin perder la coherencia en su autonomía con el discurso posterior.

El prólogo, en su función teatral, es un discurso intermediario que "asegura el paso suave de la realidad social en la sala a la ficción en la escena” (Davis 1983: 381). Así el espectador es introducido en la obra y dirigido por ella. El prólogo:

....es esencialmente un discurso mixto realidad/ficción, descripción/acción, serio/lúdico, etc. (Davis 1983: $381)$.

La naturalidad de estar familiarizados con asuntos retóricos era algo propio de las civilizaciones que ya habían alcanzado un alto nivel literario. Aunque en Roma los grandes retóricos (Cicerón, Horacio, Quintiliano) se sitúan en una época muy posterior a la de Plauto nuestro autor resulta ser un portador de una retórica espontánea, enmarcada en la tradición griega, que se exterioriza con la aplicación de técnicas de la red retórica sin la austera obediencia al rigor de la normativa.

De hecho, es bien conocido por los filólogos que de la naturaleza retórica surgió un ideal de vida y toda una gran manifestación cultural de los antiguos griegos y romanos; por lo tanto, Plauto es producto del sistema.

\section{La inventio}

Dentro de la tradición retórica, el primer paso, en el momento de la creación literaria, es buscar las condiciones adecuadas que permitan conducir la composición de la obra por un camino sencillo y de fácil acceso: ese primer paso es la denominada inventio, la primera parte del mecanismo de construcción del discurso artístico, la cual no supone la invención propiamente, en criterios convergentes de Cicerón y Barthes, sino la "extracción" de los tópicos argumentativos existentes, recopilados del contexto y ordenados mentalmente, que el autor dispondrá en la dialéctica de su creación.

La sociedad romana arcaica, heredera de la tradición teatral ilustrada es, en la época de Plauto, la manifestación clara de la necesidad del teatro como un gran exponente de cultura, educación y creación literaria. 
Los temas de la comedia latina eran, por lo general, extraídos de la temática de la Comedia de Menandro. Sin embargo, es digno de destacar cómo Plauto logró insertar argumentos foráneos en la producción literaria arcaica latina y compenetrarlos con los valores culturales y morales romanos, traslación que se evidencia a partir de la función pragmático-comunicativa que cumplen los prólogos.

Los prólogos sugieren al espectador toda una conducta social acorde con las tradiciones y costumbres de los romanos. Esas sugerencias se brindan, en su mayoría, por medio de pícaras y elocuentes informaciones ofrecidas por el prologista para surtir efecto en un auditorio deseoso de comicidad teatral y de instrucción:

¿Lo habéis entendido? Está bien.

Aquel último dice que no lo ha entendido. Acércate más. Si no tienes dónde sentarte tienes dónde pasearte, ya que obligas al histrión a mendigar. Por causa tuya no he de perder la voz... muchas veces la casualidad hace más que la prudencia...! Ya veis cúan vanos son los pensamientos de los hombres! (Captivi)

Mas ya estás aquí el viejo voceando como todos los días. Está echando de casa a la vieja que le sirve, porque recela de que sepa algo. Ahora va a visitar su tesoro no sea que se lo hayan robado. (Aulularia)

La justicia, la religiosidad de los antiguos romanos, la relación de las clases sociales, la conservación de las antiguas tradiciones, la costumbre a buenos hábitos de conducta familiar y social, la esclavitud, la conquista de la libertad, la comunicación humana constituyen el punto de partida para la elaboración de la pieza teatral. Plauto, desde sus profundas experiencias humanas domina todos estos asuntos; su ingenio y su don de palabra se combinan para recrear unas comedias con las necesidades del teatro y del público latinos.

Esta sociedad romana creciente en poderío ofreció un sistema de vida en el que Plauto pudo experimentar todos y cada uno de los asuntos por tratar. Por otra parte, su pertenencia a la clase plebeya, su vida algo "aventurera", su integración completa con la gran masa del pueblo romano y con la constante mira a la creación literaria, hacen que él represente "la solera arcaica y rural del pueblo romano, lo que lo hace ser amado y aplaudido por la multitud que llena los teatros" (Teatro latino 1963: 17).

La conquista y expansión del pueblo romano y, sobre todo, el dominio cultural en el sur de Italia (Magna Grecia) fueron circunstancias incuestionables que favorecieron la sensibilidad del "austero y agreste" pueblo romano arcaico hacia aspectos más elaborados de la cultura griega, entre ellos la práctica literaria. Plauto es también ciudadano partícipe de este momento de transición; hombre inquieto de intereses literarios y ávido de lecturas griegas, se prepara autodidacta a ser, en este contexto cultural, el iniciador de la literatura occidental romana.

Con una lengua en firme y en sistemática evolución, que propiciaba con su rigurosa normativa y profundo contenido el establecimiento y mantenimiento de una unidad institucional bien desarrollada, esta sociedad romana dio a Plauto el requerimiento retórico, ya presentado como naturalmente romano, de que "para dominar el arte de hablar bien se debe pensar bien, y para pensar bien es necesario vivir bien" (Beristáin 1988: 42).

Plauto reúne esas condiciones: las tribulaciones de una existencia pobre no le impiden "vitam bene vivere", en la medida que le permiten el conocimiento profundo del alma de su pueblo, de anhelos y conflictos, de evasiones y decepciones, de triunfos y caídas, de risas y penas, 
de chanzas y leyes... Este dominio de situaciones humanas, unido al dominio de la palabra artística, hace ver que "el verso de Plauto, cuya maestría y variedad métrica son asombrosas, expresa todas las situaciones, todos los estados de ánimos y recoge la inmensa riqueza de voces populares que reflejan los más pintorescos aspectos de la vida romana" (Teatro latino 1963: 17).

Entonces, de ese marco histórico cultural, Plauto "extrae" las ideas y los argumentos que, en forma abstracta, configuran la inventio, de la cual se pasa al segundo momento de la estructura sistemática de la retórica clásica: la dispositio o la distribución y organización de lo conseguido.

\section{La dispositio}

Encontramos en los prólogos de Plauto cierta organización, de la cual no podemos decir que resulta rígidamente sistemática, pero sí provee los constituyentes para su estructuración retórica. Al decir que tal organización no resulta sistemática, es porque algunos prólogos no contienen todos los apartados retóricos o en cierta manera se presentan un tanto soslayados, tal como en el caso del más reducido de los prólogos, el del Pseudolus:

Lo mejor es desentumecerse y ponerse derechos; una larga comedia de Plauto acaba de llenar la escena.

En la lingüística de Hjemeslev (glosemática) hay varios tipos de funciones: una de ellas es la constante que no requiere la presencia de otro funtivo para ser una función, como sí lo es la variable.

En los prólogos plautinos, las constantes tienen un carácter definido: una constante es la captatio benevolentiae, la cual es, dentro de la gran sintagmática, el tópico de relieve que aparece en todos los discursos. De esta captatio benevolentiae encontramos una gran variabilidad para su presentación: no será sólo el saludo al auditorio sino también toda una gama de estrategias discursivas para seducirlo.

Por otra parte la función variable la encontramos en los argumentos, las didascalias y los tropos argumentativos. Estos son componentes de la gran sintagmática que aparecen en unos prólogos y en otros no.

Esa función tan relevante y sobresaliente en los prólogos, cual es la captatio benevolentiae, denota en línea de máxima, la apertura del proceso de comunicación con los espectadores en el exordio, así como determina en el epílogo la conclusión del mismo proceso.

Todo inicio de discurso teatral es romper el silencio, es crear expectativas: es arbitrario, por lo que el emisor orador-prologista debe contemplar medida y prudencia, operar con sicología en la receptividad del auditorio, para captar, en efecto, la benevolencia y garantizarse, con seguridad, el éxito. Es, como dice Barthes, "exorcizar lo arbitrario de todo inicio" (Barthes 1974: 67).

La captatio benevolentiae pretende entonces seducir al auditorio, hacerlo partícipe del referente, también implicarlo, conducirlo a un estado de complicidad, de manera que la interacción sea completamente realizable a partir del mismo prólogo. La modalidad de los saludos en los cuales se espera que los oyentes tengan buena salud, es de larga tradición literaria, de tipología coloquial, cual se presenta también en las epístolas, como una fórmula codificada para iniciar o concluir la comunicación: 
Salvare iubeo spectatores optumos

Fidem qui facitis maxumi; et vos fides

(Casina: 1-2)

Otra manera con la que el prologista capta la benevolencia del auditorio es dirigirle augurios y deseos para sus negocios, lo cual demostrará así su interés y simpatía:

\footnotetext{
Ut vos in vostris voltis mercimoniis

Emundis vendumdisque me laetum lucris

Adficere atque adiuvare in rebus omnibus

Et ut res rationesque vostrorum omnium

Bene expedire voltis peregrique et domi

Bonoque atque amplo auctare perpetuo lucro

Quasque incepistis res, quasque inceptabilis;"

(Anphitruo: 1-7)
}

Estos tópicos se matizan con un fuerte grado de emotividad como en la estrategia discursiva a la que recurre Plauto para despertar el interés en la obra teatral que está por presentarse: anunciar la comedia como plautina:

\author{
... Diphilus \\ hanc graece scribit, post id rursum denuo \\ latine Plautus cum latranti nomine \\ (Casina: 33-34)
}

Perpetuam partem postulat Plautus loci

De vestris magnis atque amoenis moenibus

(Truculentus: 1-2)

El prólogo del Pseudolus, con sus dos únicos versos, hace suponer la gran fama de que gozaba Plauto, pues con él se exhorta a un público acostumbrado a escuchar sus opiniones y comentarios a través de esa recitación:

\title{
Exporgi meliust lumbos atque exsurgier:
}

Plautina longa fabula in scaenam venit.

Este prólogo, el más corto que ha llegado a nuestros días, no es el menos significativo. El semema "plautina" presupone una variedad de semas categóricos que denotan cierta actitud de agrado hacia las composiciones teatrales de Plauto. El Pseudolus está fechado en el año 191; esto significa que de las comedias que nos han llegado fueron representadas con bastante certeza, antes de ella: Asinaria, Stichus, Cistellaria, Mercator, Persa, Rudens, Trinumus, Aulalaria, Casina, Epidicus, Captivi, Curculio. Semas como apogeo del teatro latino, acondicionamiento sicológico de Plauto sobre su público espectador al cual conoce y satisface, gran aceptación de las comedias plautinas y por ello, autoridad de la capacidad creadora de Plauto. Y, otro sema importante es la facultad de suponer que cada comedia estaba precedida por su respectivo prólogo.

El prólogo del Pseudolus es sencillamente una captatio benevolentiae que lo expresa todo por sí mismo. 
La narratio es el segundo momento de la dispositio: es el relato de acontecimientos que sitúan a los espectadores y los pone en contacto con la acción de la comedia. Es el argumentum que aparece en los prólogos:

Nunc argumentum accipite atque animum advortite.

(Menaechmi: 5)

La narratio es, por lo tanto, la presentación de un estado de la cuestión, "estado de las cosas cuya dialéctica contracta" (Curtius 1975: 108) encierra el motivo del cual se parte para la exposición del discurso.

Como estructura sintagmática, la narratio está en estrecha relación con otros componentes de la dispositio. Paralela a la línea narrativa se encuentran las unidades de la argumentatio, otro sintagma de la estructura retórica.

Los argumentos son los modos persuasivos por deducción; son los razonamientos dirigidos al público y están fuera de lo ficticio, ya que por medio de ellos se pretende moralizar y adoctrinar a la sociedad, según la enseñanza de la filosofía griega. Los argumentos de los prólogos no deben ser interpretados en el sentido ciceroniano de algo ficticio que hubiera podido ocurrir, ni de lo verosímil utilizado para convencer. Ello será válido para la oratoria deliberativa y judicial.

En los prólogos, "argumentum" es un tropo irónico en el que sobresalen matices constructivos y adoctrinantes (los exempla). Además, lo verosímil del asunto supone la oposición a la crítica mientras que el prologista se interesa en convencer: es, en términos de Barthes, "la palabra simulada" frente a "la palabra ficticia" (Barthes 1974: 13). Aunque Barthes afirma que la palabra ficticia es la de los poetas, en Plauto esa palabra ficticia, por su modalidad teatral tiende más a lo filosófico, hacia una búsqueda de la verdad, una verdad de los verdaderos valores patrimoniales que podrían desvirtuarse dados los contactos derivados de la expansión de los romanos.

Además, esta retórica filosófica que Barthes retoma de Platón (sicagogía o verdadera retórica, ya que forma las almas por la palabra) la fundamentamos en los prólogos bajo los tropos elocutivos.

La tercera sección de la dispositio es el epílogo, que forma, junto con el exordio, el bloque pasional en el discurso, en cuanto puede cargar de emotividad el momento del cierre tal como el del inicio. Es aquí indispensable rescatar la originalidad de los prólogos de Plauto que difieren en el uso del epílogo propio de la tradición retórica, en cuanto está señalado por las despedidas, exhortaciones y tratos honorables a los espectadores. Resulta, por lo tanto, nuevamente una captatio benevolentiae al abandonar el prologista el escenario:

Tantum est. Valete, adeste cum silentio

(Trinummus: 22 )

Valete; adeste. Ibo; alius nunc fieri volo Quod restat, restant alii qui faciam palam.

Valete atque adiuvate, ut vos servet Salus

(Poenulus: 126-128)

Abeo. Valete, iudices iustissumi Domi, duellique duellatores optumi (Captivi: 67-68) 
Terminada la organización de los temas (la dispositio) sigue su adecuación mediante el eje paradigmático o el empleo de un lenguaje riguroso y seleccionado. Es la elocutio.

\section{La Elocutio}

Aunque Plauto se ha caracterizado por el uso de un lenguaje (habla) sencillo y de fácil comprensión para su público, el análisis de ciertas frases prologísticas denotan sus intentos de elaborar y enaltecer ese lenguaje al grado de una "solemne espiritualidad o estado de pasión", mediante una red de códigos de comunicación como perífrasis nominales y verbales, fórmulas, exclamaciones que logran el máximo nivel de receptividad por parte de los espectadores.

Tal como escribe Barthes, "lo retórico es un cuadro de desvíos del lenguaje" (Barthes 1974: 76): la expresión lingüística (verba) de los pensamientos (res) en la retórica. La elocutio es también modificar las palabras, utilizar una sinonimia figurada, llevar el lenguaje lejos del sentido normal, expresar algo por medio de otras palabras (una transformación elocutiva que genera una semántica idéntica a la original).

Plauto, así como señala Aristóteles, elabora la palabra para "salirse del discurso bajo", pero sin que este resulte enigmático.

A partir del motivo general de la dialéctica del prólogo, se desprenden dos grandes tropos que afectan la lógica del discurso; la ironia y la disimulatio. Estas dos formas de intervenir sobre el oyente constituyen verdaderos "actos perlocutivos" en los que se sugiere la contemplación de la finalidad o de la determinación de lo que es útil y lo que es perjudicial, así como lo que va de acuerdo a las leyes naturales y divinas, como se concluye de los prólogos plautinos: un ejemplo claro de esta solemnidad en el tratamiento de la disimulatio es el prólogo de Rudens (9-15):

\footnotetext{
Qui est imperator diuum atque hominum Iuppiter

Is nos per gentis aliud alia disparat,

Qui facta hominum, mores, pietatem et fidem

Noscamus, ut quemque adiuuet Opulentia.

Qui falsas litis falsis testimoniis

Petunt, quique in iure abiurant pecuniam,

Eorum referimus nomina exscripta ad Iouem.
}

o la ironia en el diálogo que sostiene "Luxuria et Inopia" en el Trinummus, al tratar Luxuria a Inopia como su hija (gnata). El prologista (Luxuria) expone que Plauto quiso que Inopia fuera "su hija", introduciendo la oración mediante la partícula "tum", la cual resulta una ironía moral, indicadora de la consecuencia de la vanidad humana:

Primum mihi Plautus nomen Luxuriae indidit;

Tum hanc mihi gnatam esse voluit Inopiam.

Sed ea huc quid introierit impulsu meo.

$(9-15)$

Barthes sostiene: "es en el nivel del conflicto social donde nació un primer esbozo teórico de la palabra simulada" (1974: 13).

La inventio es la "Res" o significado y la elocutio o "Verba" es el significante, dados a través de la dispositio. La elocutio de Plauto, que representa cómicamente los conflictos sociales, 
está revestida como palabra simulada y tiene un significante presente en todo el prólogo, el cual es metafórico además de ser insinuante e irónico. Herencia griega matizada de "vis comica itálica":

El sofista quiere ser también formador y educador del hombre: sirve a la vez a la Paideia por medio de la fuerza de la palabra (Curtius 1975: 101).

Los tropos y estrategias ilustrados son algunos de los aspectos que configuran el estilo de los prólogos de Plauto.

\section{Actio y Memoria}

Las dos restantes partes del sistema retórico, Actio y Memoria, (cuarta y quinta en la organización sistemática) tratan de la práctica locutoria o declamación o, en términos de Beristáin, "puesta en escena" o "pronuntiato" (1988: 423); se convierten en accesorios de la construcción del discurso, de manera que se pueden desligar del proceso de composición, como es la tendencia de estudios retóricos modernos, por el hecho de que "sólo tienen importancia para los discursos que realmente llegan a pronunciarse" (Curtius 1975: 108). Sin embargo, en la construcción retórica del prólogo de nuestro estudio, resultan ser la realización o "performance" de una actitud congnoscitiva y de amplia tradición cultural.

Lo anterior puede sintetizarse con el solo testimonio de la teoría y práctica del discurso de Cicerón: el manejo de esos dos apartados es ejemplarizante de la trascendencia que tienen en el éxito de los oradores en particular, por el impacto que pueden crear en el público, en el pasado y en nuestros días.

La Memoria es el proceso en el que las ideas y los argumentos existen en la organización mnemotécnica del que pronuncia un discurso. No es la retención en su memoria del discurso total, sino la acción recurrente a los tres primeros pasos del sistema retórico. La Memoria incide en la capacidad del recitador de relacionar la sintagmática con la paradigmática.

En la comedia de Plauto, para que la presentación del prólogo sea efectiva, el prologista debe tener un gran conocimiento de la temática de la obra, una especie de "almacenamiento" o reserva de tópicos: estos, hábilmente seleccionados, permitirán enriquecer el pronunciamiento ameno, organizado y congruente de elementos coherentes en la narración, insertados como digresiones, símiles, episodios y citas en el momento adecuado.

Si la Memoria requiere de sutil organización, la Actio requiere de modelos o procedimientos escénicos, capaces de despertar el entusiasmo y el interés en el público espectador.

El público romano, debido a su ya tradicional temperamento inquieto, necesitaba tener ante sus ojos un movimiento constante; por lo que el prologista, además de su entonación expresiva, necesitaba de la mímica para atender las demandas de ese público espectador. La mímica tradicional del teatro primitivo, ahora puesta en escena, recreaba el espíritu nacionalista del auditorio y rememoraba las danzas y expresiones bufonescas que la farsa, los fesceninos y la atelana les habían legado.

En tales circunstancias, el prologista constituía un actor más, y mediante su actuación, condensada en los elementos mímicos y expresivos, desarrollaba el sentimiento evocado por un 
patetismo que no se lograba sólo con el discurso compuesto y acabado. El lenguaje gestual conlleva a una reciprocidad del "pathos" o sentimiento mutuo, en donde los diferentes tópicos retóricos convergen en distintos estados anímicos y emocionales, producidos por el actor-prologista sobre el público. De hecho, Plauto se adhiere a la tradición teatral en cuanto a la estrategia de la máscara, signo de transformación individual y social.

Los rasgos de las máscaras -colores, muecas, fealdad, etc.- ridiculizando to real físico, gustaba y divertía al público; la función de disfrazar detrás de esos rasgos la realidad, permitía al autor hacer "decir" al actor el discurso de presentación.

Se completa así el análisis de la construcción del proceso de comunicación y se plantean los efectos de dicho proceso en las actitudes de los oyentes.

\section{Prólogo sentencioso}

Analizado el prólogo como un sistema retórico, trataremos en este apartado el prólogo en función de Sentencia (los gnomai de Aristóteles, que Quintiliano llamó "sententiae" juicios), más específicamente la narratio o el argumentum, ya que no dejamos de ver en los prólogos plautinos una tendencia hacia los juicios moralizantes, como norma de vida. Aún en las escuelas humanistas de la Edad Media se veía a los autores antiguos como tesoro de sabiduría.

Pero los autores no son sólo fuente de conocimiento sino también tesoro de sabiduría. En los poetas antiguos se encuentran cientos y miles de versos que condensan una experiencia psicológica o una norma de vida (Curtius 1975: 92).

La sentencia, dice Beristáin, es "la oración que expresa un lugar común con pretensiones de validez universal como norma de vida" (1988: 24).

El aparato de la retórica clásica organizó sistemáticamnte en la "tópica" los lugares comunes (loci communes): la reserva o red de argumentos conocidos que, como formas vacías o contenidos concretos, se van codificando en la construcción del discurso. Precursora de la moderna teoría de la comunicación, la "tópica", como dice J. Berrio, "representa un verdadero estudio, ordenación y clasificación de la cultura popular de la época y también de los diferentes registros que existen en los diferentes ámbitos de la sociedad" (1983: 31).

Por lo tanto, los lugares comunes tienen su fundamento en el estado latente de la sociedad, existen en todo momento y se prestan para que, quien desee componer un discurso (oratio) tenga pruebas de razonamiento y pueda despertar en el receptor la pasión.

Con el fin de lograr la máxima adhesión del auditorio, es evidente que Plauto en el prólogo sintetiza y manifiesta el mecanismo de construcción del discurso retórico: quis?, quid?, ubi?, quibus auxiliis?, cur?, quomodo?, quando? dicam, según las famosas interrogantes preparadas por Cicerón y convertidas en un histórico hexámetro. Según los teóricos, en el texto teatral, la comunicación entre la escena y la sala se logra por análogo mecanismo: "¿qué podemos representar?, ¿con ayuda de qué podemos comunicar?" (Davis 1983: 85).

Las pruebas que se obtienen en la inventio sirven de razonamiento para la argumentación de la dispositio, en la cual se presentarán como formas de exempla, comparaciones, explanationes, imitationes, recomendationes, etc. La recomendatio es el punto conclusivo del proceso 
sentencioso, el cual se inicia en la comparatio, continúa en la explanatio y logra su desarrollo pleno a manera de exempla en el artificio elocuente del orador.

$\mathrm{Al}$ igual que la ironia, la sentencia debe comprenderse en el nivel general del prólogo. Es un proceso inductivo, como los exempla, que resulta metafórico. Pero aún así, existen algunas sentencias reducidas en algunos versos pero con relación a la totalidad del prólogo.

Enimvero di nos quasi pilas homines habent.

(Captivi: 22)

Homunculi quanti sunt, quom recogito!

(Captivi: 51)

\footnotetext{
Propterea pace advenio, et pacem ad vos adfero; Iustan rem et facilem esse oratum a vobis volo:

Nam iuste ab iustis iustus sum orator datus;

Nam iniusta ab iustis inpetrare non decet;

Iusta autem ab iniustis petere, insipientia 'st;

Quippe olli iniqui ius ignorant, neque tenent.

(Anphitruo: 32-37)

Is nos per gentis aliud alia disparat

Qui facta hominum, mores, pietatem et fidem

Noscamus, ut quenque adiuuet Opulentia.

(Rudens: 10-12)
}

El mecanismo persuasivo de Plauto consiste en la similitud de unos procesos sociales foráneos (de Grecia, en el caso en cuestión) pero con la sabia intención de reflejarlos, de manera que resulten ajenos a su contexto social (Roma), procesos de los que el comediógrado tiene mayor percepción (plus sentire) con el fin de no incurrir en censura o impopularidad.

La narración del argumentum en algunos prólogos está a cargo de figuras ejemplares: el dios Lar en la Aulularia, el dios Mercurio en Anphitruo, la estrella Arturo en el Rudens, la personificación de la lujuria en Trinummus, Silenio en Baquides. En general, el prologista es una personificación de una virtud (ya sea moral, ya sea patriótica). Esta figura ejemplar es la imago -ejemplo retórico desde 100 a.C.-, la cual es un recurso literario comprobado por su gran éxito en las obras clásicas para lograr la máxima adhesión del lector o receptor (en el cumplimiento del movere, docere, delectare).

En la representación escénica, la imago, como encarnadora de una virtud, es una de las maneras más elocuentes de intervenir, es una estrategia retórica-teatral que va conduciendo los pasos del público de Plauto hacia la perfección y la búsqueda de la verdad (la retórica filosófica -Sicagogia- de Platón, del proceso educativo o la "persuasión honesta y cauta" (Eco 1986: 34). Cicerón en el "De Oratore", I, XVIII, y Quintiliano, XII, IV, pedían al orador hacer uso de ejemplos de la historia, de la mitología y la leyenda heroica.

Barthes define la sentencia o máxima como fragmento de entimema cuyo resto es virtual: el entimema es la construcción causal en que se omite la expresión pero no el contenido de una o dos premisas con el objeto de hacer más vivo y rápido el ritmo del discurso, y también para alagar la vanidad del receptor, apelando en alguna medida a su inteligencia para que él deduzca lo suprimido" (Beristáin 1988: 269). 
Si vemos el prólogo como discurso entimemático, la estructura sintagmática "narración de hechos" conlleva a la apreciación de que el mensaje o "función poética" (Jackobson 1988) tiene un contenido completo, aunque la expresión se construya en forma contracta: como un discurso sintético de la representación total.

De hecho, en el mecanismo dialéctico del prólogo, la retórica se favorece con el uso del entimema ya que el auditorio receptor va deduciendo el contenido que está expresado en un referente o contexto, en la realidad extralingüística, como un proceso cognoscitivo y pragmático. Además, el discurso se hace más vívido y contracto con el uso discursivo entimemático, ya que el entimema es el "silogismo retórico" (Eco 1986: 194).

Así, por ejemplo, el astro Arturo en el prólogo del Rudens describe el motivo de legalidad de las cosas, de naturaleza divina, y la consecuente rectitud de hábitos y costumbres de los hombres, ya que el dios supremo tiene conocimientos de sus actos y es el juez que dictará una sentencia o juicio: la premisa general es la ley divina aplicable a la naturaleza; la premisa parcial es la mejor actitud del hombre como parte de esa naturaleza (el silogismo se presentaría con las premisas "existen las leyes, el hombre se rige por las leyes", y la premisa consecuente "dios castiga de acuerdo con las leyes").

La modalidad con que se rige Plauto para armar el prólogo sentencioso es "la manera como el locutor se relaciona con su mundo; puede describirse como el predicado que rige y modifica a otro predicado de un enunciado" (Beristáin 1988: 338), o sea que aparece una jerarquía de predicados.

La competence y la performance son posibilidades de la modalidad y están secundadas por la persuasión, resultando una categoría funcional causativa, determinada por las modalidades de "querer hacer, poder hacer, saber hacer y deber hacer". La sentencia en el prólogo está instada por las condiciones existentes para su realización (la realidad); existe el "querer hacer" la transformación de estado (deseo); el "saber hacer" es la manera de influir sobre los receptores (persuasión) y el "deber hacer" se desplaza en un eje cognoscitivo con el que se logra la persuasión (los tópicos argumentativos), delimitado por un eje de la realización o "hacer pragmático".

Visto el éxito-literariedad de una actitud sentenciosa, podríamos situar el prólogo plautino -dentro de la clasificación de géneros- como un acercamiento al estilo del género epistolar: aparte del lenguaje popular característico de Plauto, notamos en la narración de los prólogos un acento muy familiar y de intercambio personal propio de la relación tan particular entre amigos o familiares. Además, es constante la inquietud de Plauto por dirigir a sus oyentes, por adoctrinarlos:

\footnotetext{
Vos omneis opere magno esse oratum volo,

Benigne ut operam detis ad nostrum greges.

(Casina: 21-22)
}

Una vez más, la modalidad "querer hacer" de la sentencia recae en la intención y deseo de reflexión (gnomai), y está orientada por el “deber hacer” del conocimiento de los lugares comunes.

\section{Conclusión}

Hemos considerado el prólogo de Plauto como una estructura retórica cargada de funciones; un código de comunicación mediante el cual se puede estudiar, analizar y comprender 
mejor toda una cultura, ya que, haciendo nuestras las palabras de Eco, "toda cultura es comunicación".

El prólogo, código retórico, por su doble articulación -res y verba- construye, en efecto, toda una unidad sintagmática concebida en la programación de complementariedad o relación del sistema retórico: Inventio, Dispositio y Elocutio; sistema que hace comprensible y comunicable una situación originaria (tópica) y que reduce la incertidumbre en la información, la cual como forma de comunicación (performance) se basa en códigos subyacentes (competence preexistente) y construye significados a través de una "función estética".

También se ha tratado de resaltar el valor retórico del prólogo, configurado en un ambiente de retórica filosófica o de verdad, según los métodos sicagógicos de Platón, que convierten el saber general en una interlocución personal (adhominatio).

A partir del marco anterior, proyectamos el sistema Inventio - Dispositio - Elocutio hacia las múltiples funciones lingüísticas, sistema en el cual, desde los postulados mismos de la retórica aristotélica, el principio de comunicación o exposición de temas, surge en los prólogos como una "desigualdad" en las condiciones cognoscitivas de los participantes de la comunicación: el prologista recita el prólogo con la intención de informar algo acerca de la comedia, pero a la vez, el mensaje contiene supuestos que el oyente reconoce y acata como consejos o exhortaciones. El prologista marca esa "desigualdad de saber" y, por saber más, lo comunica al que entiende menos, siendo útil para el perfeccionamiento de la vida en sociedad.

Entonces, nuestra conclusión nos lleva a establecer el prólogo como una comunicación con sus componentes retóricos: tópicos o referentes, propósitos o funciones, un medio circundante localizado en el tiempo y en el espacio, la forma del mensaje, etc., y sobre todo, a establecer la intención pragmática de la retórica prologista, modalidad que, enriquecida con los recursos teatrales, provoca efecto en aquellos a quienes va dirigido: en los espectadores, sin dejar de producir, además, sensaciones satisfactorias en los lectores de diferentes épocas, aquellos que por lo menos saben leer la obra "en las condiciones de novedad en que nació".

\section{Bibliografía}

Barthes, R. 1974. Investigaciones retóricas I. La antigua retórica. Argentina: Editorial Tiempo contemporáneo.

Bayet, J. 1972. Literatura latina. Barcelona: Ariel.

Beare, I. 1972. La escena romana. Buenos Aires: Eudeba.

Beristáin, H. 1988. Diccionario de retórica y poética. México: Editorial Porrúa.

Berrio, J. 1983. Teoría social de la persuasión. Barcelona: Editorial Mitre.

Cicerón. 1956. De oratore. París: Les Belles Letres. 
Curtius, E. 1975. Literatura europea y Edad Media latina. Tomo I. México: Fondo de Cultura Económico.

Davis, P. 1983. Diccionario del teatro. Barcelona: Paidós Comunicación.

Eco, U. 1986. La estructura ausente: introducción a la semiótica. Barcelona: Editorial Lumen. Hjemslev. 1971. El lenguaje. Madrid: Gredos.

Jackobson, R. 1988. Lingüística y poética. Madrid: Ediciones Cátedra S.A.

Quintiliano. 1911. Instituciones oratorias. Madrid: Imprenta de Perlado, Páez.

Teatro Latino. 1963. Madrid: E.D.A.F. 
